\title{
Stopping the Spread of Germs
}

\author{
Sarah Wortmann ${ }^{1}$ \\ ${ }^{1}$ Journal of Conceptual and Applied STEM Education
}

June 24, 2020

\section{Overview}

Students will begin by exploring how germs spread from person to person. They will investigate how hand washing and social distancing are effective ways to stop the spread of germs. Students will use the engineering design process to create a hands-free soap dispenser.

\section{Vocabulary}

- Germ

- Virus

- Social Distancing

\section{Objectives}

- Students will learn how properly washing your hands and practicing social distancing are effective ways to stop the spread of germs.

- Students will learn how to create a hands-free soap dispenser using PVC piping, hot glue, and string.

\section{Materials}

- A Little SPOT Stays Home: A Story about Viruses and Safe Distancing by Diane Alber

- Engineering Design Notebook

- Bottle of Soap

- PVC Piping

- String

- Hot Glue (used only by the teacher)

- Yard Stick

\section{Lesson}

\section{Part 1: Germs and Viruses Overview (10 minutes)}

1. Ask students to define germs and viruses. Respond to ideas and definitions and discuss ways we can stop the spread of germs and viruses. 
2. Read A Little SPOT Stays Home: A Story about Viruses and Safe Distancing by Diane Alber. Ask students what they learned about germs, viruses, and social distancing. As a class, define these vocabulary words in the students' own words. Write these definitions on an anchor chart and refer to them throughout the lesson.

\section{Part 2: Design and Build Your Own Hands-Free Soap Dispenser (45 minutes)}

1. After handing out the engineering design notebooks, students will first work on their own to plan and draw their designs for the soap dispensers. Students will then get into groups of 4 and discuss their designs and decide on the best path forward.

2. Hand out PVC piping, string, measuring stick, and bottle of soap to each group to be used in the prototype design. Inform students that hot glue is available upon request; the teacher will apply it per the group's instructions.

3. Students will work together to create their soap dispenser prototype. This will include building with the PVC piping, string, bottle of soap, and hot glue. Students will use the yard stick to measure. Students will update their plans and designs in their engineering design notebooks.

4. Once the prototypes are complete, the testing process will begin. Most students will use the PVC piping to create a foot-operated soap dispenser. Students will test their prototypes and evaluate the results. Results will be recorded in the engineering design notebooks.

5. Students will be given the opportunity improve and redesign their prototypes as needed. They will be given another opportunity to test their designs and see if the improvements worked.

\section{Part 3: Whole-Class Discussion (5 minutes)}

Which designs worked? Why is a hands-free soap dispenser design so important? Will this design help in the stop of spreading germs? What other ways can we stop the spreading of germs?

\section{Homework}

Research the following questions to discuss in class.

- How many germs are on your hands at any given time?

- How long should you wash your hands?

- How many germs are killed by washing your hands? 